\title{
Interactive comment on "Hydrographic survey over the Carlsberg Ridge in May 2012" by Hailun He et al.
}

\section{Anonymous Referee \#2}

Received and published: 10 September 2019

This manuscript introduces hydrographic observations collected over the Carlsberg Ridge in the northwest Indian Ocean. The authors have created a hydrographic dataset that comprises observations collected by a ship and by Argo floats. They identify key water masses, conduct particle tracking experiments, and use the observations to evaluate two re-analysis products. With a few exceptions, the standard of written English is acceptable and the quality of the figures is, on the whole, satisfactory. I think that this manuscript will require substantial revision prior to publication.

Point 1. My primary criticism of this manuscript is that it lacks a clear message; I am unsure of what it is that the authors want me to remember as being important or new. The authors correctly point out that the northwest Indian Ocean is not well sampled, and so any new observations from this region are of value. However, beyond 
simply presenting these new observations, the authors, in my view, do not sufficiently demonstrate what we can learn from them. The discussion section, which is where the value of the new observations should be made explicit, largely restates points already made in the results section. It does not cite a single piece of literature. I think that the discussion section needs to be substantially revised: it should explain the value of the observations in the context of relevant literature and, ideally, it should set out a clear argument.

Point 2. The methods outlined in section 2 need to be better explained. The authors note the depth-mean offsets between temperature and salinity observations collected by the ship's CTD and the expendable CTDs (xCTD), and between the xCTDs and an Argo float. Firstly, the implication is that these offsets used to calibrate the xCTD observations - but this should be stated explicitly. Secondly, it is not clear to me whether: (1) XCTD observations are being compared to both ship and Argo observations; or (2) whether ship observations are being compared to XCTD observations, which are then being compared to Argo observations. If the former, which of the two sets of offsets are the authors using for the calibration? If the latter, are the authors calibrating observations from all Argo floats using an offset calculated from just one Argo float? Furthermore, do publicly available observations from the Argo programme need to be calibrated? Are they already calibrated when they are made available for download?

Point 3. The authors point out several times that adding the Argo observations to the ship CTD and XCTD observations enables them to examine mesoscale processes. This may well be the case, but I think that they need to carefully consider the temporal and spatial scales of mesoscale activity in the Arabian Sea. For instance, they include Argo observations from up to $200 \mathrm{~km}$ from their section over the Carlsberg Ridge: is this distance less than the Rossby radius at this latitude? Furthermore, Table 1 indicates that the observations were collected over a period of one month. Are the authors confident that these observations may be presented in one section (Figure 4) as if they were a synoptic snapshot?

OSD

Interactive comment
Printer-friendly version

Discussion paper 
Line-by-line comments. Page 1, line 14. I am not sure what the authors mean by "renewed" in this context

OSD

Page 1, lines $15-17$. I am not really sure what this sentence means

Page 1, paragraph beginning line 21. This paragraph is not relevant

Page 2, paragraph beginning line 13. This paragraph outlines the reasons for studying the hydrography of the Carlsberg Ridge region, but none of the points raised is revisited later in the paper. The paper would be much improved if, when discussing the results, the authors revisited some of these points - for instance, saying how these new observations help to determine the movements of sporadic hydrothermal activity.

Page 2, line 17. I do not agree that the results presented "shed new light into the basic energy theory of ocean circulation"

Page 2, line 33. It would be nice to have the distance between the CTD and the XCTD station given in $\mathrm{km}$.

Page 3, line 6. Again, it would be nice to have the distance between the Argo and the xCTD station given in $\mathrm{km}$.

Page 4, Figure 1. I think that panel (a) is too small to be of much use: I can't really see the detail because the symbols are too close together. Panel (a) might work better as a separate figure. Similarly, I cannot distinguish individual vorticity contours in panel (b). Contours are not labelled, and the contour interval is not given. The vorticity field should be presented using filled contours, similar to the ADT field in panel (d).

Page 5, line 28. I assume that the data extracted from the re-analysis products are along the same section as the observations, but this should be said explicitly.

Page 6, line 8 (equations). The symbol $w$ is not defined. I assume it is vertical velocity? The authors should state whether they are performing their particle tracking experiments using 2D or 3D velocity.
Interactive

comment
Printer-friendly version

Discussion paper 
Page 6, line 10. The authors give the start and end time of the particle tracking experiments here, and not in the caption of Figure 6.

OSD

Page 6, line 19. I do not understand what the authors mean when they say that the "wind stress curl highlights the strong seasonal variations". Also, wind stress curl is not shown in a figure.

Page 6, line 27. The statement that warm-core eddies "seem to release footprints in the wind stress curl" does not make sense. I would have thought that the wind influences the eddies and not the other way around. Furthermore, when talking about wind stress curl, the authors refer to Figure 1 (b), but the figure caption says that this panel shows wind velocity and vorticity, not wind stress curl.

Page 6, 29. It is not clear why the westward current is "remarkable". Has this feature not been observed before? Is it significant? Do the authors believe that it cannot be explained by their observations, or by existing theory?

Page 7, line 7. Strictly speaking, the boundary between the tropics and the subtropics is around $23.5^{\circ} \mathrm{N}$, so all of the observations being considered here are from the tropics. Consequently, the use of the word subtropical is misleading. Subsequent uses of these terms should also be revised.

Page 7, line 7. I do not think the authors are justified in grouping PGW and RSW as RSPGIW. In Figure 2, the water masses are observed to be separate, and the authors have acknowledged the different densities of the two water masses.

Page 7, line 18. The observations from the World Ocean Atlas presented in Figure 3 are from a climatology and should not, therefore, be described as a snapshot.

Page 7, line 19. The authors have not marked north and south on Figure 3 , so it is difficult for the reader to make sense of statements such as "the thermocline... deepens northward".

Page 7, line 22. I do not really agree with the authors' point about ventilation. The
Interactive

comment 
outcropping of isotherms visible in Figure 3 is from within the mixed layer - it is not clear that "subsurface" water is then able to take part in air-sea interaction.

OSD

Page 7, line 28. The authors do not explain why their observations show that saline intermediate waters are PGW and RSW - nor do they explain why this is not clear in the climatology.

Page 7, line 31. Why have the authors chosen the $22 \mathrm{~kg} \mathrm{~m}-3$ isopycnal?

Interactive

comment

Page 7, line 33. It is hard to compare Figure $1 \mathrm{~b}$ and Figure 3, because Figure $1 \mathrm{~b}$ uses degrees and Figure 3 uses $\mathrm{km}$.

Page 7, line 333. I do not understand what is meant by projecting the outcrop point in the wind vector field.

Page 8, Figure 2. I am not sure why the mean temperature-salinity curves have been plotted. They are not mentioned in the text and they distract from the new observations.

Page 9, line 1. I don't think that the thermocline can be described as descending "sharply".

Page 9, line 5. I don't understand what is "remarkable" about the southward extension of salty water.

Page 9, line 15. Again, I don't understand why the velocity field in the upper ocean is "remarkable".

Page 9, line 19. I think the authors need to label features of interest - eg CCE2 - on Figure 4. As it stands, it is quite hard to see what the authors want the reader to look at.

Page 9, line 22. The authors need to discuss, somewhere in the paper, the significance of the westward-propagating disturbance. At the end of the paper, I have no better idea of what is it and why it might be significant than I had at the start. 
Page 9, line 26. When comparing the observationally derived geostrophic current and the current fields from the re-analysis products, have the authors considered that the current fields in the re-analysis products might contain ageostrophic components, eg Ekman flow?

Page 10, first paragraph. I do not understand the argument that this paragraph is trying to make. There are several ideas that are not fully explored and which are insufficiently referenced. The authors seem to be contrasting "customary ventilation theory" and its corresponding meridional flow with "potential vorticity analysis" and its corresponding zonal flow. This strikes me as being a massive oversimplification; at the least, it requires a much more detailed explanation. Much of this material - as well as the extra explanation I would like to see added - probably belongs in the introduction.

Page 10, line 1. In what way are explanations of ASHSW and RSW pathways "ambiguous"? This statement needs to be referenced, evidenced and more fully explained, either here or in the introduction.

Page 10, line 5. This sentence is poorly expressed.

Page 10, second paragraph. The authors should explain clearly why they break up the particle tracking results into latitudinal bands - is this because they suspect different processes/currents are causing differences in circulation between these bands? Also, this paragraph should make some attempt to elucidate these processes and to explain what's new and important about these results. At present, the text just explains what the reader can already see in the figure.

Page 10, line 14. I do not agree that this looks like flow in the summer Somali Current.

Page 10, third paragraph. Again, some discussion of processes is needed here.

Printer-friendly version

Page 10, line 25. Are there papers or technical reports available that explain methodological differences between the Hycom and Soda re-analyses? Would more thorough research negate the need for speculation?

Interactive

comment

\section{Discussion paper}


Page 10, line 27. It is not clear to me what is meant by the "dynamic core" of the ocean general circulation model.

OSD

Page 10, line 33. I dislike the description of geostrophic current as an "alternative result for the ocean current". Geostrophic flow is an important part of ocean circulation and is perfectly valid in its own right.

Page 11, conclusions section. The particle tracking results are not mentioned in the conclusion.

Page 11, line 2. The authors have not discussed baroclinic modes in the results section, so it does not make any sense to the reader when the concept is introduced in the discussion section. Furthermore, are the authors certain that baroclinic mode is an appropriate concept in this instance?

Page 11, line 11. It is not correct to say that you integrate density to get the geostrophic current.

Page 11, line 20. I do not think that the authors have shown how "the present analysis shows potential data applications for the future".

Page 14, Figure 3. Using $\mathrm{km}$ as the horizontal co-ordinate is unhelpful, given that in the text what is actually interesting is the location in degrees north. The authors should also mark on features of interest discussed in the text, such as the eddies.

Page 16, Figure 5. Given that the westward-propagating disturbance is so little discussed, I do not think that this figure adds anything to the paper.

Interactive comment on Ocean Sci. Discuss., https://doi.org/10.5194/os-2019-62, 2019.
Interactive

comment
Printer-friendly version

Discussion paper 